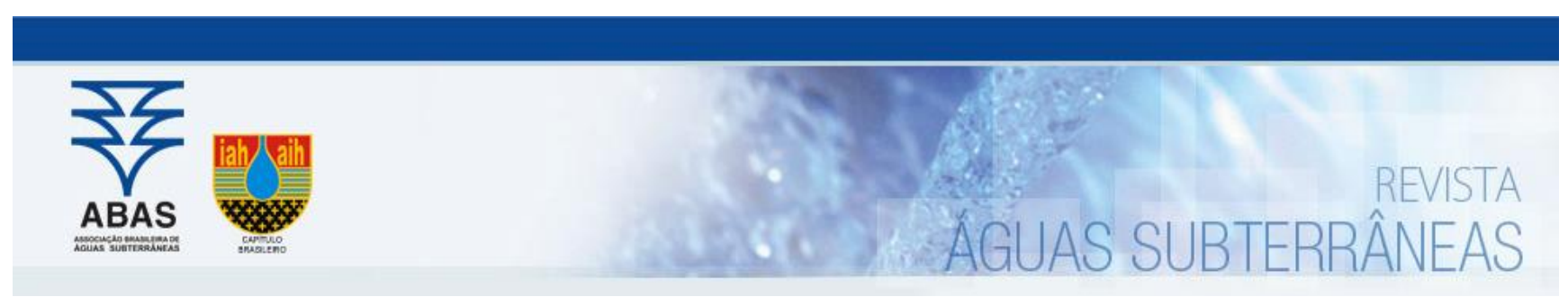

Artigos

\title{
Dessalinizador solar do tipo cascata aplicado em poços artesianos no interior da Paraíba
}

\section{Cascade type solar desalinizer applied in artesian wells in Paraíba interior}

\author{
Maria Karolina Borba Cardoso1; Yohanna Jamilla Vilar de Brito1; Karyna Steffane Silva1; Camylla Barbosa Silva1; Carlos Antônio \\ Pereira de Lima1 ${ }^{\text {; Keila Machado de Medeiros }}{ }^{2}$ \\ 1 Universidade Estadual da Paraíba (UEPB), Departamento de Engenharia Sanitária e Ambiental (DESA), Campus de Campina \\ Grande - PB \\ 2 Universidade Federal do Recôncavo da Bahia (UFRB), Centro de Ciência e Tecnologia em Energia e Sustentabilidade \\ (CETENS), Campus de Feira de Santana - BA
}

$\rrbracket$ borbakarol654@gmail.com, yohannajvb@gmail.com, karynasteffane@hotmail.com, camyllabsilva@hotmail.com, caplima@uepb.edu.br, keilamedeiros@ufrb.edu.br

Palavras-chave:

Semiárido.

Escassez hídrica.

Poços.

Dessalinização solar.
Resumo

Para o consumo humano e as demais atividades domésticas, os moradores do semiárido brasileiro utilizam águas de diversas fontes. Portanto, a análise da qualidade da água é de vital importância, principalmente por utilizarem águas de poços com alto teor de salinidade. Em contrapartida, é um território de elevada incidência de radiação solar, que é fundamental para a dessalinização via energia solar. Desta forma, nesta pesquisa foram realizadas análises físicoquímicas de alcalinidade, cloreto, condutividade elétrica, dureza, pH, sódio e turbidez, com o objetivo de determinar a qualidade da água antes e após o processo de dessalinização solar, como também foi avaliado o rendimento do dessalinizador. As águas dessalinizadas apresentaram resultados muito eficientes na remocão dos parâmetros físico-químicos estudados, estando os mesmos de acordo com os padrões de potabilidade exigidos pela Portaria do Ministério da Saúde vigente no país.

Keywords:

\section{Abstract}

\section{Semiarid.}

Water scarcity.

Wells.

Solar desalination.

Revisado por pares.

Recebido em: 13/02/2020.

Aprovado em: 13/05/2020.
For human consumption and other domestic activities, residents of the Brazilian semiarid use water from different sources. Therefore, the analysis of water quality is of vital importance, mainly because they use well water with high salinity content. In contrast, it is a territory with a high incidence of solar radiation, which is essential for desalination via solar energy. Thus, in this research, physical-chemical analyzes of alkalinity, chloride, electrical conductivity, hardness, $\mathrm{pH}$, sodium and turbidity were carried out, in order to determine the water quality before and after the solar desalination process, in addition, the performance of the desalinator was evaluated. The desalinated water showed very efficient results in the removal of the physicochemical parameters studied, with the same according to the potability standards required by the Ministry of Health Ordinance in force in the country.

\section{INTRODUÇÃO}

A terra tem um total de 1400 milhões de quilômetros cúbicos de água, dos quais $97 \%$ são encontrados nos oceanos. Dos $3 \%$ restantes, dois terços são em forma de icebergs, lençóis de gelo e geleiras. Isso deixa apenas $1 \%$ de água doce que são encontrados em rios, lagos, lagoas, poços, entre outros. Do valor de $1 \%$ de água doce, metade é proveniente de água subterrânea (KANADE \& BHATTACHARYA, 2016).

A população global aumentou de 2 bilhões em 1950 para uma população atual de 7,4 bilhões. A disponibilidade global de água per capita tem uma relação inversa, diminuindo por um fator maior que 3 durante este período. No entanto, existem razões pelas quais essa conclusão não é global, como o fato da distribuição do aumento populacional não ser uniforme (LASKHMI et al., 2018).

Há uma escassez aguda de abastecimento de água, energia e alimentos, e a demanda deve aumentar de 40 a $50 \%$ até 2050, devido ao aumento da população (KALAIR et al., 2016). $\mathrm{O}$ desafio da água em áreas remotas é considerado um dos fatores mais críticos enfrentados pelo consumo humano e pelas necessidades da agricultura.

A disponibilidade de água per capita em muitos locais do mundo está constantemente diminuindo. Há muitos fatores que são responsáveis pelo esgotamento da água doce, alguns deles dizem respeito ao aumento da população, industrialização, urbanização, transporte, entre outros, tornando um 
grande desafio para as gerações atuais e futuras. A água é essencial para várias atividades do cotidiano como cozinhar, cultivar e beber (TIWARI et al., 2003).

O Brasil tem posição privilegiada no mundo em relação à disponibilidade de recursos hídricos. 0 maior consumo brasileiro está na irrigação que utiliza $46 \%$ do total de recursos hídricos retirados, a cifra é coerente com o destacado papel econômico do agronegócio no Brasil. Em segundo lugar está o consumo humano urbano com $27 \%$, ficando o uso industrial em terceiro com $18 \%$ do total. Apesar da grande disponibilidade, a distribuição dos recursos hídricos no Brasil é bastante desigual em termos geográficos e populacionais. Embora a Amazônia possua $74 \%$ da disponibilidade de água, a sua bacia hidrográfica é habitada por menos de $5 \%$ da população brasileira, o que explica a baixa utilização do recurso (ANA, 2007).

\subsection{Estresse hídrico no Semiárido Brasileiro}

O semiárido nordestino é o mais chuvoso do planeta, com pluviosidade média de $750 \mathrm{~mm}^{-a n \mathrm{~N}^{-1}}$, onde ocorre a irregularidade das chuvas e possuem temperaturas relativamente elevadas. Assim, a convivência com o semiárido não corresponde extinguir a seca, mas adaptar-se ao ambiente de forma inteligente, que corresponde principalmente ao armazenamento de água com o impedimento da evaporação. Dentro desse contexto, a exploração das águas subterrâneas, a partir da perfuração de poços tubulares, se torna uma importante alternativa para o suprimento hídrico nas comunidades rurais do semiárido (SILVINO et al., 2016).

Segundo a Articulação no Semiárido Brasileiro - ASA, o semiárido brasileiro tem área $1.128 .697 \mathrm{~km}^{2}$ (ocupando cerca de $12 \%$ do território nacional), englobando 1.262 municípios, com cerca de 27.870.241 habitantes vivendo na região, considerando a delimitação atual divulgada em 2017 (a Resolução 11 de 13 de novembro de 2017 - da Superintendência do Desenvolvimento do Nordeste SUDENE). Os estados com maior número de municípios na região semiárida são Bahia (278), Paraíba (194), Piauí (185), Ceará (175), Rio Grande do Norte (147) e Pernambuco (123). Integram ainda, a região semiárida os municípios nordestinos dos estados do Maranhão, Alagoas e Sergipe. 0 único estado que não está na Região Nordeste e possui municípios no Semiárido é Minas Gerais, com 91 municípios, o Maranhão passou a fazer parte do Semiárido Legal em 2017 (IBGE, 2019).

No semiárido do Nordeste brasileiro é claro a carência de água, afetando o comportamento da biota e das comunidades que vivem nessa região. Os problemas existentes comumente estão vinculados em colocar em funcionamento as políticas públicas, direcionadas a gestão dos recursos hídricos. Diferentes políticas públicas com base em uma solução tecnológica específica têm passado pelo semiárido, como ondas: a pequena açudagem, os poços com dessalinizadores por membranas e as cisternas são algumas delas (ANA, 2012).

Um exemplo de técnicas de captação e armazenamento está às cisternas de placas, que são hermeticamente fechadas e captam água das chuvas por meio de calhas (MALVEZZI, 2007). Desta forma, a natureza dos fatores físicos explica o ambiente que caracteriza a paisagem semiárida, onde os solos rasos e pedregosos cobertos por vegetação de caatinga desafiam o homem, que faz uso destes recursos para sobrevivência, resistindo ao retorno das grandes estiagens (RAMALHO, 2013).

\subsection{Qualidade das águas}

No Brasil, o padrão de qualidade da água destinada ao consumo humano é definido pela Portaria $n^{\circ} 5$, de 28 de setembro de 2017 que visa à proteção da saúde pública e o controle de substâncias potencialmente prejudiciais, como micro-organismos patogênicos, substâncias tóxicas ou venenosas e elementos radioativos, que se aplica à água destinada ao consumo humano proveniente de sistema e solução alternativa, coletiva ou individual de abastecimento de água. Os parâmetros são dispostos com seus respectivos valores máximos permitidos - VMP (CASTRO, 2014).

A qualidade da água potável é determinada principalmente pela quantidade de sólidos totais dissolvidos - STD. É importante ressaltar que países diferentes tem regulamentação distinta para o nível de STD, por exemplo, nos Estados Unidos é de 500 mg.L-1 , enquanto na Índia é de 250 mg.L-1. Os STD na verdade compreendem sais inorgânicos e pequenas quantidades de matéria orgânica dissolvida em água. Os principais constituintes dos STD são íons de cálcio, magnésio, sódio e potássio, e ânions de carbonato, bicarbonato, cloreto, sulfato e nitrato (KIM et al., 2019).

A viabilização do uso de águas salobras para o consumo humano através de métodos alternativos de diminuição dos sais e que proporcionem a eliminação de microrganismos patogênicos, que não causem impacto ambiental e sejam economicamente viáveis para pequenos agricultores é de suma importância (MARINHO et al., 2012). Nas comunidades rurais do Nordeste brasileiro, a utilização de águas subterrâneas de poços tubulares é uma alternativa ao abastecimento d'água. No entanto, há uma grande limitação na utilização desses poços para enfrentamento da escassez hídrica, que é o elevado teor de sais dissolvidos (NEVES et al., 2017).

\subsection{0 uso da dessalinização solar}

A dessalinização solar é uma alternativa promissora que pode suprir as necessidades humanas de água doce com uma fonte de energia adepta do ambiente. Exibe uma considerável vantagem econômica em relação a outros processos de desalinização, devido ao recurso livre de custos e à redução do custo de operação e manutenção. Os sistemas de dessalinização solar são usados com uma ampla variedade de designs, configurações, geometria e materiais de fabricação (ELANGO et al., 2015). Embora seja uma tecnologia simples, a purificação de água através da dessaliniazação solar é bastante eficaz, produzindo água com alto grau de pureza, superior às águas comerciais engarrafadas (FOSTER \& AMOS, 2005).

A dessalinização solar pode ser direta ou indireta, dependendo de como a energia solar poderá ser aplicada. Sistemas de dessalinização solar direta, também conhecido como destiladores solares, às águas dessalinizadas são produzidas diretamente no coletor solar, enquanto os sistemas de dessalinização solar indireta a energia solar é recolhida como energia térmica ou elétrica sendo, por sua vez, utilizada para conduzir a dessalinização (AHMED et al., 2019).

A água, quando em estado de pureza, não possui sabor e odor próprios. Por esta razão, a água dessalinizada é desagradável 
ao paladar sendo desejável na água potável a presença de algumas substâncias, em baixas concentrações, que promovem a sua palatabilidade. Entre substâncias mais frequentemente encontradas nas águas naturais, encontram-se: os carbonatos, sulfatos, cloretos e nitratos de cálcio, ferro, magnésio e sódio, além de alguns compostos de silício e, frequentemente, vários compostos orgânicos (BRANCO, 1986).

Nesta pesquisa, foi analisado o desempenho de um dessalinizador solar tipo cascata, utilizando águas de poços artesianos com o objetivo de obter uma água com padrões de potabilidade para o consumo humano.

\section{MATERIAL E MÉTODOS}

O protótipo do dessalinizador solar foi construído na Universidade Estadual da Paraíba - UEPB, na cidade de Campina Grande - Paraíba, a uma latitude $7^{\circ} 13^{\prime} 11^{\prime \prime}$ sul e longitude $35^{\circ} 52^{\prime} 31^{\prime \prime}$ oeste, com altitude média de 550 metros, no Laboratório de Pesquisa em Ciências Ambientais - LAPECA, do Departamento de Engenharia Sanitária e Ambiental - DESA do Centro de Ciências e Tecnologia - CCT.

\subsection{Origem das águas salobras}

Nesta pesquisa, foram dessalinizadas águas de poços artesianos que são utilizadas pelas comunidades locais para as suas necessidades diárias. Os poços estão localizados nos municípios de Caturité-PB (Poço P1) com latitude $7^{\circ} 25^{\prime} 13^{\prime \prime}$ sul e longitude $36^{\circ} 01^{\prime} 38^{\prime \prime}$ oeste, com altitude média de 405 metros com área de 118,2 km², e Juazeirinho-PB (Poço P2) a uma latitude $7^{\circ} 04^{\prime} 06^{\prime \prime}$ sul e longitude $36^{\circ} 34^{\prime} 40^{\prime \prime}$ oeste, com altitude média de 553 metros com área de 463,8 km² e com o objetivo de obter uma água com padrões de potabilidade para o consumo humano.

\subsection{Sistema de dessalinização}

O sistema de dessalinização via energia solar do tipo cascata com seus componentes é ilustrado na Figura 1. O mesmo é composto por três partes principais: a placa absorvedora de calor, o vidro de condensação de água dessalinizada e o sistema de isolamento térmico. 0 dessalinizador possui comprimento de $145 \mathrm{~cm}$ e largura de $55 \mathrm{~cm}$, apresentando uma área de $0,78 \mathrm{~m}^{2}$. 0 mesmo opera com uma inclinação de $17^{\circ}$ orientado para o norte, com o intuito de maximizar a absorção de calor. A placa absorvedora possui dimensões de $140 \mathrm{~cm}$ de comprimento e $50 \mathrm{~cm}$ de largura, tem formato de cascata, a mesma foi pintada em preto fosco para aumentar a absorção da radiação, além disso, o formato em cascata favorece o tempo de permanência da água salobra no sistema. A tampa de vidro no topo do dessalinizador tem $3 \mathrm{~mm}$ de espessura e a distância entre o vidro e a placa absorvedora é de $4 \mathrm{~cm}$. 0 dessalinizador é todo isolado com fibra de vidro para diminuir as perdas de calor para o ambiente.



\subsection{Modo operacional do dessalinizador}

O dessalinizador foi alimentado com água salobra coletada nos poços artesianos P1 e P2, a operação do sistema foi realizada em batelada, a água salobra na alimentação transcorre a placa absorvedora e é aquecida pela energia solar. Ao absorver o calor a água salobra evapora e condensa no lado interno do vidro, em virtude da temperatura do vapor de água ser superior à temperatura do vidro. Em seguida, a água condensada é coletada por uma calha, sendo contabilizada por uma proveta graduada.

O sistema de dessalinização, foi monitorado em 04 experimentos nos dias 26, 27, 28 de novembro de 2019 e outro no dia 02 de dezembro de 2019, no intervalo de 07:00 às 17:00 horas, posicionado em uma área estratégica sem sombreamento. Além disso, foi usado termopares da Alutal Pt-100, para medir a temperatura em diferentes pontos do sistema, que inclui a temperatura da água salobra, temperatura do vidro, temperatura da placa absorvedora, e do isolante térmico, as medições foram executadas a cada 30 minutos. Durante 
todo o experimento também foi medido o índice de radiação global, através do radiômetro - solarímetro KIMO SL100.

\subsection{Análises físico-químicas das águas}

Antes e no final dos experimentos, as amostras de águas salobras e dessalinizadas foram submetidas às análises físicoquímicas, com o intuito de obter o seu grau de potabilidade.
No decorrer dos experimentos, a água dessalinizada era recoIhida e medida o seu volume em intervalos de 30 minutos, computando o volume total no final dos experimentos. A caracterização da água a ser dessalinizada foi feita por meio das análises de $\mathrm{pH}$, condutividade elétrica, cloretos, dureza, alcalinidade, sódio, temperatura, turbidez e cor, os métodos utilizados estão indicados na Tabela 1, e seguiram as metodologias descrita no Standard Methods for Examination of Water and Wastewater (RICE et al., 2012).

Tabela 01 - Metodologia das análises físico-químicas empregadas

\begin{tabular}{lll}
\hline Parâmetro & Unidade & Métodos \\
\hline $\mathrm{pH}$ & adimensional & Potenciométrico \\
Condutividade elétrica & $\mu \mathrm{S} . \mathrm{cm}^{-1}$ & Condutivímetro \\
Cloreto & $\mathrm{mg} \mathrm{Cl} \cdot \mathrm{L}^{-1}$ & Titulométrico - Mohr \\
Dureza & $\mathrm{mg} \mathrm{CaCO} 3 . \mathrm{L}^{-1}$ & Titulométrico - EDTA \\
Alcalinidade & $\mathrm{mg} \mathrm{CaCO} \cdot \mathrm{L}^{-1}$ & Titulométrico com indicador \\
Sódio & $\mathrm{mg} \mathrm{Na} \mathrm{L}^{-1}$ & Fotometria de chama \\
Temperatura & ${ }^{\circ} \mathrm{C}$ & Termopar \\
Turbidez & $\mathrm{NTU}$ & Nefelométrico \\
Cor & $\mathrm{uH}$ & Colorimétrico \\
\hline
\end{tabular}

\section{RESULTADOS E DISCUSSÃO}

\subsection{Perfis de temperaturas e de radiação}

O comportamento do desempenho do dessalinizador foi caracterizado pelas diferentes temperaturas que ocorre no seu interior. Desta forma, a diferença de temperatura entre o vapor de água e o vidro foi fundamental para o aumento da eficiência do dessalinizador. Nas Figuras 2 e 3 pode ser observada a comparação entre a variação das temperaturas, da água, do vidro, do ambiente, do isolante, da placa e da radiação solar, para os poços P1 e P2.

Figura 2 - Perfis de temperatura e radiação solar para o poço P1




Figura 3 - Perfis de temperatura e radiação solar para o poço P2

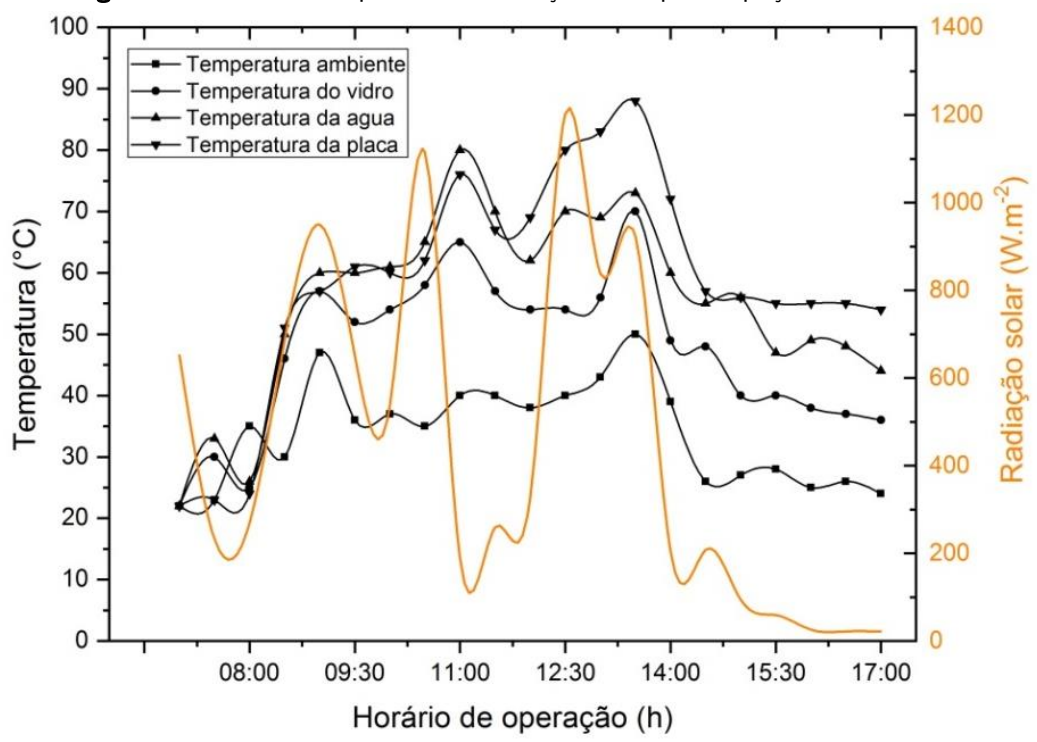

Na Figura 2, para um valor máximo de radiação solar de 1166 W. $\mathrm{m}^{-2}$, foi verificado que as temperaturas da placa e da água permaneceram próximas, em torno de $60^{\circ} \mathrm{C}$ e $63^{\circ} \mathrm{C}$, respectivamente. Ainda na Figura 2, podemos observar que as variações de radiação foram atribuídas às oscilações climáticas como a passagem de nuvens, no qual fez com que a temperatura da água fosse ligeiramente maior do que a da placa, beneficiando o processo de dessalinização, pois a água mais quente favorece a evaporação da mesma, e esta variação permaneceram próximas ao longo de todo o experimento.

A partir da Figura 3, foi obtido um valor máximo de radiação de $1221 \mathrm{~W} \cdot \mathrm{m}^{-2}$, e este foi superior ao encontrado na radiação do poço P1. Além disso, foi observado que as temperaturas da placa e da água foram de $80^{\circ} \mathrm{C}$ e $70{ }^{\circ} \mathrm{C}$, respectivamente. Esta maior diferença de temperatura, ocorreu devido o maior índice de radiação ter ocasionado uma maior absorção de caIor pela placa. Bouzaid et al. (2019) relataram que um novo design do dessaliniador melhora a evaporação, aumentando o tempo de permanência da água salobra na placa de absorção.

De maneira geral, as temperaturas do dessalinizador nas Figuras 2 e 3 aumentaram de maneira gradual pela manhã, e após as 14:00 horas as temperaturas decresceram gradativamente, conforme a diminuição da intensidade de energia solar no sistema. Resultado semelhante foi encontrado por Hansen (2017) que estudou diferentes configurações de dessalinizadores solar.

\subsection{Produtividade do dessalinizador}

As Figuras 4 e 5 ilustram a produtividade da água dessalinizada com a variação das temperaturas da placa, da água, do vidro e do ambiente, para os poços P1 e P2, respectivamente.

Figura 4 - Perfis de temperatura e produção de água para o Poço P1

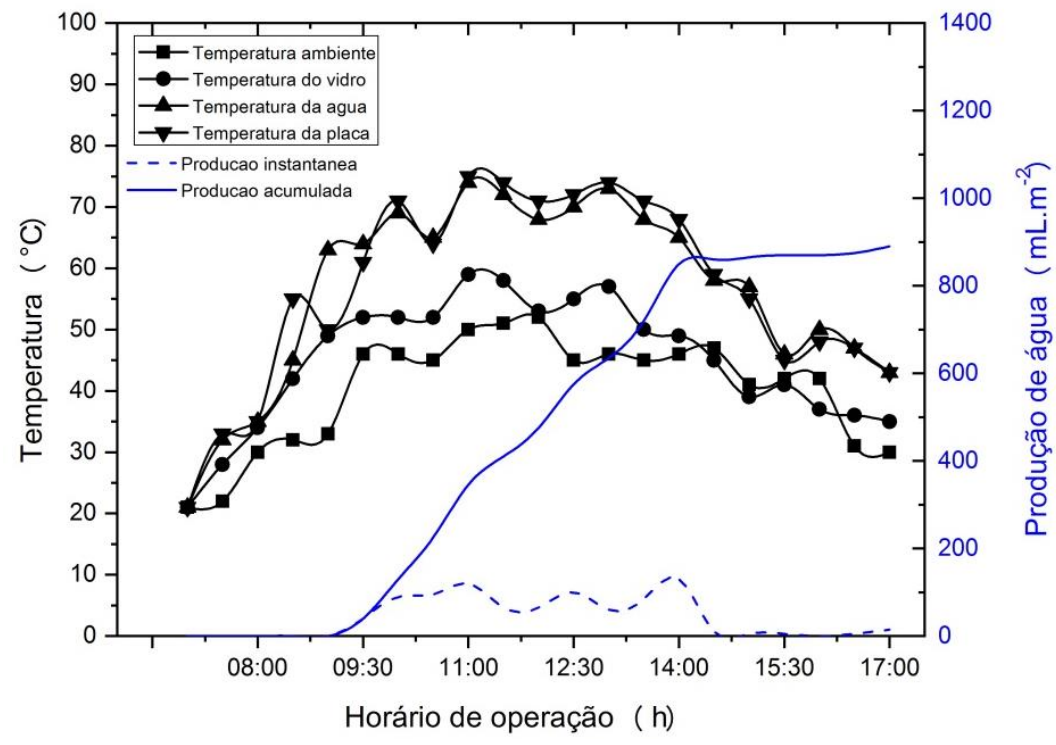


Figura 5 - Perfis de temperatura e produção de água para o Poço P2

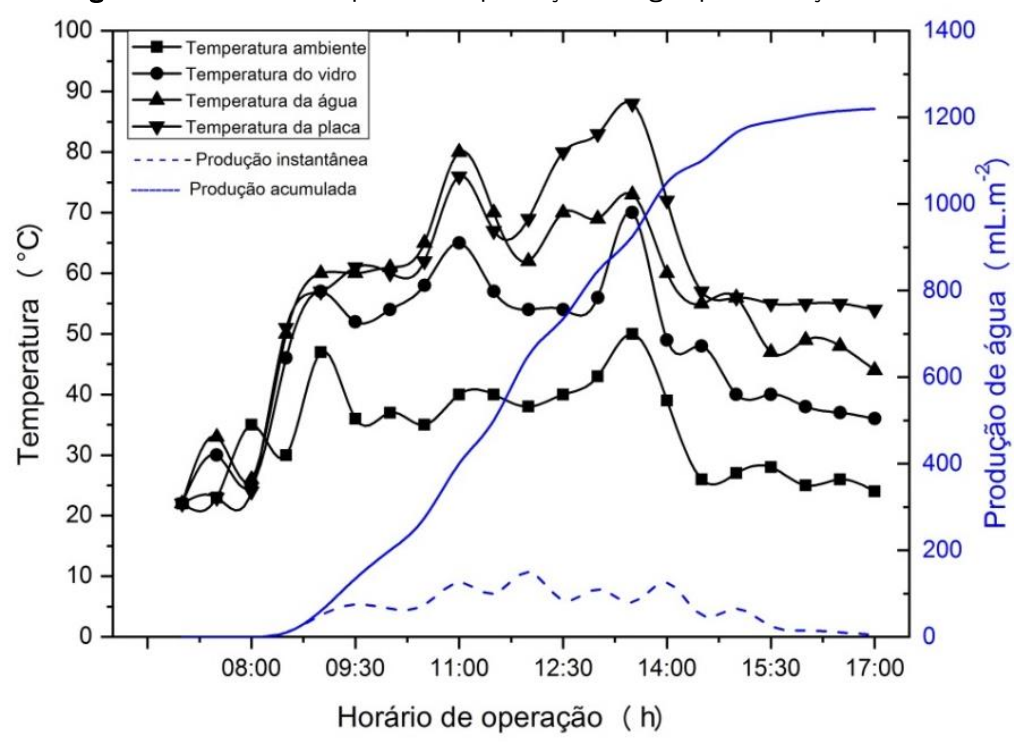

A partir da Figura 4, foi observado que o volume de água instantânea foi diretamente proporcional à temperatura, ou seja, à medida que a temperatura da água foi maior, ocorreu um aumento no volume de água dessalinizada. Deste modo, às 11:00 e as 13:00 horas, quando as temperaturas da placa estavam em seus pontos máximos, houve um aquecimento da água, ocorrendo a sua evaporação e posterior condensação, sendo observado para ambos os casos os maiores volumes após 30 minutos, obtendo uma produtividade de água em torno de $130 \mathrm{~mL} . \mathrm{m}^{-2}$ e $139 \mathrm{~mL} . \mathrm{m}^{-2}$, respectivamente.

Comportamento semelhante foi encontrado na Figura 5, pois às 14:00 horas, quando a temperatura da placa estava em seu ponto máximo, foi constatada uma produtividade de água em torno de $150 \mathrm{~mL} . \mathrm{m}^{-2}$ após 30 minutos que esta temperatura foi alcançada. Além disso, foi verificado que após as temperaturas da água e da placa chegarem a seus pontos máximos, posteriormente houve um declínio no intervalo entre uma coleta e outra, ocorrendo à redução da água dessalinizada instantânea. Nas Figuras 4 e 5, o maior volume obtido ocorreu após 30 minutos da temperatura máxima da placa, devido o tempo em que a água leva para aumentar a sua temperatura, evaporar, condensar na superfície do vidro e escoar para ser posteriormente recolhida.

Ainda nas Figuras 4 e 5, podemos observar uma produção de água de $891 \mathrm{~mL} . \mathrm{m}^{-2}$ para uma radiação de 1166 W.m-2 em $\mathrm{P} 1$, e de $1224 \mathrm{~mL} \cdot \mathrm{m}^{-2}$ para uma radiação de $1221 \mathrm{~W} \cdot \mathrm{m}^{-2} \mathrm{em}$ $\mathrm{P} 2$, confirmando que a maior produtividade de água dessalinizada foi relacionada com a maior radiação solar e que foi obtida para o poço P2, comprovando que as variações climáticas diárias interferem diretamente na produção de agua dessalinizada, uma vez que os experimentos foram realizados no mesmo local. Nafey (2000), afirma que a radiação solar é o parâmetro que mais afeta a produtividade, deste modo, a produtividade cresce na medida em que aumenta a radiação solar. Segundo Abujazar et al. (2016), a produtividade está diretamente correlacionada com a quantidade de radiação solar, a temperatura ambiente, a umidade relativa e a velocidade do vento. Ziabari et al. (2013) constataram que uma fina camada de água na placa absorvedora de calor ajudou a evaporação da água salobra e melhorou a produtividade.

\subsection{Características físico-químicas das águas}

Os experimentos de dessalinização foram executados das 07:00 as 17:00 horas, antes do inicio e no final do processo três amostras de água foram coletadas para a realização de análises físico-químicas da água salobra e dessalinizada, respectivamente. Na Tabela 2 são apresentados os resultados para os poços P1 e P2.

Tabela 2 - Análises físico-químicas das águas salobras e água dessalinizada

\begin{tabular}{|c|c|c|c|c|c|}
\hline \multirow{2}{*}{ Análises } & \multicolumn{2}{|c|}{ Poço P1 } & \multicolumn{2}{|c|}{ Poço P2 } & \multirow{2}{*}{ VMP** } \\
\hline & $A B *$ & $A D^{*}$ & $A B *$ & $A D *$ & \\
\hline pH (adimensional) & 7,5 & 6,2 & 7,5 & 6,0 & $6,0-9,5$ \\
\hline Condutividade elétrica $\left(\mu \mathrm{S} . \mathrm{cm}^{-1}\right)$ & 3190,0 & 16,6 & 7220,0 & 17,6 & $10-100$ \\
\hline Alcalinidade (mg $\left.\mathrm{CaCO}_{3} \cdot \mathrm{L}^{-1}\right)$ & 230,0 & 57,0 & 302,0 & 49,0 & 125,0 \\
\hline Cloreto (mg Cl-..-1) & 404,7 & 14,2 & 291,1 & 35,5 & 250,0 \\
\hline Dureza (mg $\left.\mathrm{CaCO}_{3} \cdot \mathrm{L}^{-1}\right)$ & 285,0 & 5,0 & 205,0 & 25,0 & 500,0 \\
\hline Sódio (mg Na+. $\left.\mathrm{L}^{-1}\right)$ & 420,0 & 0,0 & 520,0 & 0,0 & 200,0 \\
\hline Temperatura $\left({ }^{\circ} \mathrm{C}\right)$ & 27,40 & 27,0 & 27,4 & 27,0 & 30,0 \\
\hline Turbidez (NTU) & 3,0 & 2,0 & 2,0 & 2,0 & 5,0 \\
\hline Cor $(\mathrm{uH})$ & 8,4 & 5,1 & 25,0 & 15,0 & 15,0 \\
\hline
\end{tabular}

* AB.= Água Bruta; AD.= Água Dessalinizada.

** Valor máximo permissível pela PRC $n^{\circ} 5$, de 28 de setembro de 2017, Anexo XX. 
A partir da Tabela 2, podemos observar que as águas brutas oriundas dos poços P1 e P2 encontram-se com os padrões de potabilidade acima dos valores máximos permissíveis e regulamentados pela Portaria de Consolidação $n^{\circ}$ 005/2017 (BRASIL, 2017), evidenciando que as mesmas não são próprias para o consumo humano. Diferentemente, do ocorrido para as águas brutas dos poços P1 e P2, que após o processo de dessalinização verificou-se que todos os parâmetros medidos neste experimento se enquadram dentro dos valores máximos permissíveis pela Portaria, constatando uma redução para os seguintes parâmetros: de 96,49\% e 87,80\% para o cloreto; de $75,22 \%$ e $83,77 \%$ para alcalinidade e de $98,24 \%$ e $87,80 \%$ para a dureza. Além disso, podemos destacar ainda para os poços P1 e P2, uma redução significativa de 99,48\% e 99,76\% para a condutividade elétrica e de $100 \%$ para o sódio, constatando a grande eficiência do dessalinizador estudado.

\section{CONCLUSÕES}

Diante dos resultados apresentados, concluiu-se que as temperaturas do sistema, o volume de água instantânea, bem como a produtividade de água dessalinizada foram diretamente proporcionais à radiação solar. Além disso, para as águas dessalinizadas dos dois poços (P1 e P2), foi verificado uma redução significativa de todos os parâmetros físico-químicos estudados, estando os mesmos de acordo com os padrões de potabilidade para o consumo humano, exigidos pela Portaria do Ministério da Saúde vigente no país. Portanto, ficou evidenciado a grande eficiência do dessalinizador solar tipo cascata, podendo o mesmo ser aplicado em comunidades isoladas do semiárido paraibano, onde ocorre grande escassez de água potável.

\section{AGRADECIMENTOS}

Os autores agradecem ao Conselho Nacional de Desenvolvimento Científico e Tecnológico (CNPq) e a Coordenação de Aperfeiçoamento de Pessoal de Nível Superior (CAPES) pela concessão das bolsas.

\section{REFERÊNCIAS}

ABUJAZAR, S. S.; FATIHAH, S.; RAKMI, A. R.; SHAHROM, M. Z. The Effects of Design Parameters on Productivity Performance of a Solar Still for Seawater Desalination: A Review Mohammed. Desalination, v. 385, p. 178-193, 2016. https://doi.org/10.1016/i.desal.2016.02.025

AHMED, F. E.; HASHAIKEH, R.; HILAL, N. Solar Powered Desalination - Techonology, Energy and Future Outlook. Desalination, v. 453, p.54-76, 2019. https://doi.org/10.1016/j.desal.2018.12.002

ANA. Agência Nacional de Águas. Panorama do enquadramento dos corpos d'água do Brasil, e Panorama da qualidade das águas subterrâneas no Brasil. Brasília: 2007.

ANA. Agência Nacional das Águas (Brasil). Panorama da qualidade das águas superficiais no Brasil: 2012/ Agência Nacional de águas. Brasília, 2012.

BOUZAID, M.; ANSARI, O.; TAHA-JANAN, M.; MOUHSIN, N.; OUBREK, M. Numerical Analysis of Thermal Performances for a Novel Cascade Solar Desalination Still Design. Energy Procedia, v. 157, p. 1071-1082, 2019. https://doi.org/10.1016/i.egypro.2018.11.274
BRANCO, S. M. Hidrobiologia Aplicada à Engenharia Sanitária. 3 ed. CETESB/ASCETESB, São Paulo, SP, 1986.

BRASIL. Portaria de Consolidação $n^{\circ} 5$, de 28 de setembro de 2017 do Ministério da Saúde. Dispõe sobre os procedimentos de controle e de vigilância da qualidade da água para consumo humano e seu padrão de potabilidade. Brasília, 2017.

CASTRO, J. S. O.; JÚNIOR, B. T. B.; PONTES, A. N.; MORALES, G. P. Potabilidade das Águas Subterrâneas para o Consumo Humano na Área do Polo Industrial de Barcarena-Pará. Enciclopédia Biosfera, v.10, n.19, p.2921-2934, 2014.

ELANGO, T.; KANNAN, A.; MURUGAVEL, K. K. Performance Study on Single Basin Single Slope Solar Still with Different Water Nanofluids. Desalination, n. 360, p.45-51, 2015. https://doi.org/10.1016/i.desal.2015.01.004

FOSTER, R. E.; AMOS, W.; EBY, S. Ten Years of Solar Distillation Application Along the U.S.-Mexico Border. Solar World Congress, International Solar Energy Society Orlando, Florida, August 11, 2005.

HANSEN, R. S; MURUGAVEL, K. K. Enhancement of Integrated Solar Still Using Different New Absorber Configurations: An Experimental Approach. Desalination, n. 422, p. 59-67, 2017. https://doi.org/10.1016/i.desal.2017.08.015

IBGE. Instituto Brasileiro de Geografia e estatística. Estimativas Populacionais dos Municípios Brasileiros. Disponível em: http://www.ibge.gov.br/home/estatistica/ populacao/estimativa2013/. Acesso em: 31 jun. 2019.

KANADE, P. S.; BHATTACHARYA, S. S. A guide to filtration with string wound cartridges. Elsevier, Amsterdam, 2016.

KALAIR, A. R.; ABAS, N.; HASAN, Q. U.; KAILAR, E.; KAILAR, K.; KANADE, P.; BHATTACHARYA, S. S. A guide to filtration with string wound cartridges. 1. ed. Elsevier, p. 1-10, 2016.

KIM, J-S.; JAIN, S.; LEE, J-H.; CHEN, H.; PARK, S-Y. Quantitative Vulnerability Assessment of Water Quality to Extreme Drought in a Changing Climate. Ecological Indicators, n.103, p. 688697, 2019. https://doi.org/10.1016/j.ecolind.2019.04.052

LASKHMI, V.; FAYNE, J.; BOLTEN, J. A Comparative Study of Available Water in The Major River Basins of the World. Journal of Hydrology, n.2, p.510-532, 2018. https://doi.org/10.1016/i.jhydrol.2018.10.038

MALVEZZI, R. Semiárido: Uma Visão Holística. Brasília: Confea, 2007.

MARINHO, F. J. L.; ROCHA, E. N.; SOUTRO, E. A.; CRUZ, M. P.; TAVARES, A. C.; SANTOS, S. A.; MARCOVICZ, F. Destilador Solar Destinado a Fornecer Água Potável para as Famílias de Agricultores de Base Familiar. Revista Brasileira de Agroecologia. n.7, p. 53-60, 2012.

NAFEY, A. S.; ABDELKADER, M.; ABDELMOTALIP, A.; MABROUK, A. A. Parameters Affecting Solar Still Productivity. Energy Conversion \& Management. v. 41, p.1797-1809, 2000. https://doi.org/10.1016/S0196-8904(99)00188-0

NEVES, A. L. R.; MAILSON, P. A.; LACERDA, C. F.; CHEYL, H. R. Aspectos Socioambientais e Qualidade da Água de Dessalinizadores nas Comunidades Rurais de Pentecostes. Revista Ambiente e Água, v. 12, n. 1, p. 124-135, 2017. https://doi.org/10.4136/ambi-agua.1722

SILVINO A. S., VIGLIO J. E. FERREIRA L.C. A Conservação da Caatinga em Diferentes Arenas do Semiárido Brasileiro, Sustentabilidade em Debate. Centro de Desenvolvimento Sustentável da Universidade de Brasília, v. 7, n. Especial, Brasília, 2016.

tDeb.v7n0.2016.18758
https://doi.org/10.18472/Sus- 
TIWARI, G. N.; SINGH, H. N.; TRIPATHI, R. Present Status of Solar Distillation. Solar Energy, n.75, p. 367-373, 2003. https://doi.org/10.1016/i.solener.2003.07.005

RAMALHO, M. F. J. L. A fragilidade Ambiental do Nordeste Brasileiro: 0 Clima Semiárido e as Imprevisões das Grandes Estiagens. Sociedade e Território, v. 25, n. 2, p. 104-115, 2013.
RICE, E. W.; BAIRD, R. B.; EATON, A. D.; CLASCERI. Standaid Methods. For the Examination of Water and Wastewater. American Public Washington, DC, 22 ed., 2012.

ZIABARI, F. B.; SHARAK, A. Z.; MOGHADAM, H.; TABRIZI, F. F. Theoretical and Experimental Study of Cascade Solar Stills. Solar energy, v. 90, p. 205-211, 2013. https://doi.org/10.1016/j.solener.2012.12.019 